\title{
One spring a year, and only one youth in life
}

Bertus F. Jeronimus, PhD., University of Groningen, Department of Developmental Psychology, Interdisciplinary Center Psychopathology \& Emotion regulation (ICPE).

This paper is not the copy of record and may not exactly replicate the final, authoritative version. Cite as: Jeronimus, B.F. (2021). One spring a year, and only one youth in life. Times higher education, 210304. Accepted 12-02-2021

This first year of the coronavirus pandemic made us suffer from loss and struggle to adapt to new social routines, while over 110 million became infected and 2.4 million died. Europe is largely in lockdown while various virus mutations are spreading around the globe. In this world adolescents and emerging adults (aged 16-25) have to figure out how to relate to others and unfold their wings to find a place for themselves. Simone de Beauvoir (1958) aptly described this special position of youth in society as "one spring a year, and only one youth in life." 1 Youth is a transformative phase of development in which we rebel, experiment, and investigate how society works, while we acquire the skillset to build social and intimate relationships and contribute to society. Youngsters author their personal narrative, who they are and what they can do, and use interpersonal interactions to grow differentiated adult personalities. Youngsters lay the groundwork for a healthy and meaningful life, and exactly this process became under pressure, which, without proper action, may translate into future problems.

\section{One colorless day after another ticks away}

A key ingredient of a horror story is an isolated place. Social distancing has quarantined youth in their homes, increasingly alienated and lonely, eyeing strangers a little more warily than before. One year of downtime and restricted freedom evaporated most contextual structure and disconnected our students from their peers, friends, family, teachers, sports, night life, parties, sleepovers, side jobs, internships, travel, festivals, and picnics in the park. All outlets closed. This may seem a minor grief compared to the tragedies on the intensive care and nursing homes, but to youth, it means the world. Students previously spend most of their time accompanied by peers, who surpass parents as a key source of intimacy and support, but now spend most time alone. Rites de passage failed to launch, from graduation, jobs, trips, and celebrations to dates and sex (which typically occur within peer groups). How can you build an adult life when you stay at home and do little else?

Part of our youth entered a downward spiral. Today most students around the globe are grieving and experience loneliness, dread over the coming months, pessimism about their future, worry about their close relations becoming ill, and loss of motivation to undertake activities they previously enjoyed. One third reports anxiety and/or sleep problems, irritability, listlessness, and depression, and since the end of 2020 these numbers are on the rise. Almost $40 \%$ describe their current lives as unfulfilling. Substance abuse became common to cope with stress, loneliness, and boredom (cannabis, alcohol, amphetamines), and may turn into lifelong addiction. Excessive sedentary time and sleep translated into obesity which they carry into their future. Many students seem on the verge of collapse and one step away from burnout. Vulnerable youth reach their

\footnotetext{
1 “Un seul prin temps dans l'année, et dans la vie uni seule jeunesse." Simone de Beauvoir in Memoirs of a Dutiful Daughter (1958).
} 
"tipping point" earlier, and without proper care, their mental health can deteriorate rapidly. European youth mental health facilities report increases in acute psychological crisis $(+60 \%$ in some regions) and more complex problems, from severe depressions, suicidal ideation and selfharm, to acute anorexia (which requires forced feeding) and severe psychosis, and a rise in maltreatment and (sexual) abuse and neglect.

The literature shows that youth mental health problems often have far-reaching secondary consequences as they hamper educational attainment and social network formation and romantic relationships, and getting and maintaining a job, which increases the odds of a dire economic future and lower well-being, because these people feel they have little to contribute to society. Persistent anxiety, gloom and suspiciousness can become embedded in their developing personalities, which influences how they perceive and navigate their worlds for years to come. We should be particularly mindful of underprivileged students who are prone to exploitation, abuse, hidden anxiety, educational delays and school dropout, and already had to work harder. When positive-legal avenues to status and stimulation are closed more youngsters are lured into risky and criminal behavior, as indicated by the age-crime curve, and the severe riots we witnessed in Europe and the United States. Too many students $(\sim 40 \%)$ have no support network to ask for help because everyone tries to reduce their contact during lockdown. Even if you prefer pure economic arguments, it is wise to invest in this corona generation now, to prevent enormous future costs.

\section{Purpose and meaning}

I call on all with influence to prioritize youth in pandemic policies because they suffer most from distress, adjustment, and missed opportunities. We have a moral duty to help students from all backgrounds to participate in society on an equal footing, and to restore the patterned activities of their daily lives that give them meaning, purpose, and a sense of belonging. That is civilization. Students need teachers and sport coaches as gatekeepers to stimulate talent development, positive self-talk, and persistence, and identify problems and co-rumination, to refer them to professionals. Remote learning cannot substitute for social interaction as students can only truly develop and learn when they feel safe and seen. Teachers can provide students with a routine, and help them to comprehend that mental symptoms are normal during a pandemic, stimulate the pursuit of creative outlets (music, dance, drawing, play), to go into nature, exercise, connect with others, and to focus on what they can control. Teachers can make students see that they can drag out feet the entire way kicking and screaming or that they can regroup and adapt. Let us pressure our governments to prioritize youth wellbeing and education, next to the medical-economic considerations that now dominate our strategies. There is only one youth in life, and most of us spend more time in retirement than childhood and adolescence combined. Youngsters have a shorter time horizon which can make 2021 seem insurmountable, but we can reassure our students that once this pandemic and most social containment policies are history, the sun still comes up, and the world still spins. Together, we can do this.

\section{References}

Jeronimus, B.F. (2020). Personality and the Coronavirus Covid-19 Pandemic. University of Groningen Press. https://www.doi.org/10.21827/5ed9ebc01d65f 